\title{
DÜBLIN
}

Technological University Dublin ARROW@TU Dublin

\section{A Critical Realist Approach to Engineering Ethics}

\author{
Eddie Conlon \\ Technological University Dublin, edward.conlon@tudublin.ie
}

Follow this and additional works at: https://arrow.tudublin.ie/schmuldistcon

Part of the Other Engineering Commons

\section{Recommended Citation \\ Conlon, E. (2015). A Critical Realist Approach to Engineering Ethics. IEEE International Symposium on Technology and Society, Dublin, Ireland, 11-12 November.DOI: doi:10.1109/ISTAS.2015.7439443}

This Conference Paper is brought to you for free and open access by the School of Multidisciplinary Technologies at ARROW@TU Dublin. It has been accepted for inclusion in Conference papers by an authorized administrator of ARROW@TU Dublin. For more information, please contact arrow.admin@tudublin.ie, aisling.coyne@tudublin.ie,gerard.connolly@tudublin.ie. 


\title{
A Critical Realist Approach to Engineering Ethics
}

\author{
Eddie Conlon \\ College of Engineering and Built Environment \\ Dublin Institute of Technology \\ Dublin, Ireland \\ edward.conlon@dit.ie
}

\begin{abstract}
This paper is focused on the teaching of engineering ethics (EE). Through a focus on safety and the lens of what sociologists call the agency/ structure relationship it examimes various approaches to this teaching. Drawing on Critical Realism it argues there are deficiencies in both the dominant approach and a number of proposed alternatives as they suffer from various forms of conflationism . By drawing on Critical Realism (CR) a more robust agenda for teaching engineering ethics can be developed. It is argued that $\mathrm{CR}$ offers a basis for understanding the range of factors which lead to accidents and disasters. It allows for a fuller consideration of agency/structure relations and the importance of changing the contexts in which engineers work in order to allow them to hold paramount the health, safety and welfare of the public.
\end{abstract}

Keywords-engineering ethics; safety; strcture/agency realtions; critical realism.

\section{INTRODUCTION}

This paper is about the teaching of engineering ethics (EE). Through a focus on safety and the lens of what sociologists call the agency/ structure (individual/society) relationship it examimes various approaches to this teaching. Drawing on Critical Realism [1] it argues there are deficiencies in both the dominant approach and a number of proposed alternatives as they suffer from, what Archer has called, various forms of conflationism [1]. It will also be argued that by drawing on Critical Realism (CR) a more robust agenda for teaching engineering ethics can be developed. The paper proceeds as follows. First the accident at BP Texas City in 2005 is discussed. It is shown that rather than being the fault of individuals it resulted from problematic features of BPs corporate culture and strategy. It is shown that the accident shares common features with other accidents as identified in the literature. The question is then posed as to how engineering students should be taught about such accidents and what should be the focus of such teaching. It is argued that the dominant approach, with its emphasis on the agency of individual engineers, is deficient in that it cannot adequately address the range of issue identified. It is also argued that some proposed alternatives do not address these inadequacies as they focus on structure alone. Finally it is argued that CR offers a basis for understanding the range of factors which lead to accidents and disasters. It allows for a fuller consideration of agency/structure relations and the importance of changing the contexts in which engineers work in order to allow them to hold paramount the health, safety and welfare of the public.

\section{BP TEXAS CITY}

On March 23, 2005 fifteen workers were killed and 180 injured in a series of explosions and fires during the start-up of an isomerisation (ISOM) unit at the third largest refinery in US owned by $\mathrm{BP}^{1}$. All the dead were contract workers. BP blamed the blast on "a series of failures" by staff: "Had the individuals who were operating the facilities and running the facilities followed the written instructions, the explosion would not have happened." Its investigations blamed the incident on a series of "surprising and deeply disturbing" mistakes by plant operators and supervisors. BP said company investigators "didn't find evidence of budgetary decisions which were an immediate cause or critical factor in this terrible tragedy."

The view of the Chemical Safety Board (CSB) was somewhat different. Its preliminary report found that highlevel decisions to defer overhauls, cut staff, and rein in costs contributed to the accident. BP had cut fixed costs by about $25 \%$ from 1998 to 2004. These cuts "adversely impacted maintenance expenditures and infrastructure at the refinery." The CSB chairperson said that BP displayed "all the symptoms of a failed safety culture": poor maintenance; inadequate staff training; outdated procedures; malfunctioning equipment; overworked and over-stretched staff without adequate supervision. The final CSB report found that the disaster "was caused by organizational and safety deficiencies at all levels of the BP Corporation" including inadequate corporate response to safety problems, ignoring regulations and a focus on production over safety. BP's attribution of the incident to worker error was put in context by the final report that said these workers had each worked almost 40 consecutive shifts. Such intense working periods are characteristic of turnaround and maintenance when there is a major rush to get capital-intensive plants back into operation. The use of contract workers for maintenance operations increased the risk of an accident.

An additional problem was that for management " bad news was not encouraged, incidents were often ineffectively investigated and appropriate corrective action not taken." In late 2004 consultants were commissioned to survey refinery

\footnotetext{
${ }^{1}$ The information on this accident is taken mainly from [2] but see also
} 
staff on safety. Workers said they had stopped reporting injuries and incidents, due to pressure from management.

A final issue was that the plant was ineffectively regulated. The blowdown drum and safety relief valve at the centre of the incident were undersized: federal regulations required a study of the relief system, but BP was unable to produce documents showing this study had actually been performed: "By 2005 the required relief valve study was 13 years overdue". The plant had an average of one fire a week in the ten years leading up to the accident. The CSB was critical of the regulatory authorities for its minimal regulation of a large number of hazardous plants. Further, BP had lobbied against new rules which would have forced it to upgrade the ISOM unit. Mac Sheoin [2] argues that the accidents and others like it stem "from common technical, organizational, and managerial problems, many of which are directly related to economic decisions".

What is of significance from the above is the contrast between BPs explanation focusing on the actions of individuals and the CSB approach which highlights economic, organisational and social factors which contributed to the explosion. Its report accords with research on accidents which argues that "attempts to find an identifiable culprit (should) not obscure the more subtle causes of failure which are typically complex, multiple and rooted in the social and organisational properties of the overall sociotechnical system associated with hazardous technology" [4]. These causes recur in disparate engineering sectors [5].

The factors identified by the CSB report are not uncommon in other accidents. Dien et al. [6] identify recurrent features of "organisational accidents". In doing so they argue that "the scientific community involved in the field of accident study agrees on the fact that if any event (accident, incident or crisis) is generated by direct and immediate causes ("human errors" among others), it has been induced and favoured by underlying local causes or conditions (specific technical and ergonomic conditions, local modes of personnel management, environmental characteristics, etc.) and more global organisational conditions which may be at the origin of the local conditions or have an impact on the direct or immediate causes (e.g. weak safety culture, primacy of production pressure, failure or lack of communication between business entities, technocratic reorganisation, a deteriorating social climate, etc.)."

Accidents have an historical background and an unfavourable organisational context in as much as a number of decisions and unfavourable circumstances progressively generate a pre-accident situation long before the triggering of the accident itself. Accidents can be seen to have an incubation period when multiple predisposing factors accumulate. A trigger event then provokes the onset of the accident [4]. The recurrent factors identified by Dien et al. are: 1. Weakness of the organisational safety culture; 2. Complex and inappropriate organisation; 3. Limits of operational feedback; 4. Failure of the control organisations; and 5. Production pressures.
Taking a more radical and integrated approach Tombs [6,7] offers what he calls a "political economy of corporate killing." In explaining "safety crimes" he argues for an approach based on political economy which places their production within "prevailing systems of economic, social and political organisation, dominant value systems and beliefs, and the differential distribution of power. Grasping the complexity of safety crimes means addressing a series of inter-related factors, not least dynamically (that is, historically) and beyond the level of the nation state". He argues that there is a need to consider a range of factors ranging from the individual through to the structural operating at four analytically distinct levels. Individuals need to be placed in the structures in which they operate and this means taking account of their immediate work group, workplace, company and the wider environment in which the company operates. This leads to a focus on the relationship between profit and safety, management and workers (including the capacity of the latter to organise and challenge the former and the extent to which management heed warnings from below), the role of the state in regulating safety and supporting a "voice" for workers and state business relations: corporations operate within "particular kinds of social order with certain legal bases guarantees and powers". In this context the advent of neo-liberal regimes with commitments to deregulation and the valorisation of risk has had a detrimental effect on workplace safety ${ }^{2}$. What is significant about this approach is that it seeks to integrate mechanisms operating at different levels into explanations of management and worker interactions and their effects on safety. It focuses on the distribution of power and "exposes as socially specific what is taken for granted, revealing how what is, was not always so, and need not necessarily be, with existent states of affairs only comprehensible in the context of macro-level social processes, on both national and international levels." [7].

\section{ENGINEERING ETHICS}

The above raises a challenge for those seeking to teach EE and who want to empower engineers to hold paramount the safety, health and welfare of the public. The dominant approach $[10,11,12,13]$ to EE uses case studies to focus on the resolution of ethical dilemmas by individual engineers. These often involve clashes between engineers and managers and focus on the capacity of engineers to resist managerial pressures and/or engage in whistleblowing. The approach draws on moral philosophy and codes of ethics, "standards of responsibility" [15], as the basis of ethical decision making. EE should help "engineers to take their professional responsibilities to heart" [14]. It assumes that not only can ethical problems be solved at the level of the individual but that engineers can act on their solutions. As a result, those using this approach tend to focus on individual failings as the key impediments to responsible action [see 15].

In explaining the Challenger Disaster Davis focuses on

${ }^{2}$ See [9] for a discussion of engineering and neo-liberalism 
"microscopic vision" and that fact the Lund (an engineer) stopped thinking like an engineer and more like a manager: "Lund had a professional duty to act like an engineer...For an engineer public safety is the paramount consideration. The engineers could not say the launch would be safe, so, Lund should have delayed the launch. Seven people died, in part at least because Lund did not do what, as an engineer, he was supposed to do" [16]. This explanation seems to ignore the analysis presented above about the importance of an incubation period generating a pre-accident situation and the range of contextual factors that contribute to this and focuses solely on the individual engineer: "A solid grounding in moral philosophy, a personal moral code, and a commitment to professional responsibility are assumed to inoculate us from the weakness of will" [17]. By ignoring the structural context in which engineering takes place this approach leads to moralism as unrealistic expectations are placed on engineers. One particular problem is what is referred to as the "problem of many hands" in that engineers are just one of many actors involved in complex organisational and technical processes. Further, the freedom of engineers is restricted in that they typically work in "hierarchical organisations and have little room to follow their own choices" [17]. This refers to what is known as the captivity of engineering to corporate and managerial agendas [18].

A related problem with this approach is its commitment to value neutrality. While engineers are to practice engineering ethically they are not to commit to any particular set of values. Engineers are to strive for "creative middle ground" [15] solutions and EE teachers are to avoid preaching [19]. There would seem to be an assumption that not only are creative middle ground solutions desirable but also that they are attainable (in that the needs of all parties can be met) and implementable without addressing the wider context in which problems arise.. The contexts that underlies cases is not called into question. Thus this approach does not lead to the questioning of the wider purpose of engineering or the role of engineers in reproducing power relations and patterns of privilege in society. There is a crucial link between the ontological assumption that $\mathrm{EE}$ teaching should focus narrowly on the practice of individual engineers and the political assumption that ethical dilemmas can be resolved at this level without changing the context in which engineers work. This is why some have called for a focus on institutional ethics rather than individual ethics. Underlying this work is the recognition that "If the engineers claim for safety have to survive in a context dominated by competition for money and power, regulation with an ethical content may be the engineers life jacket" [20, see also 21]. This is part of a wider call for alternative approaches which focus on the realities of engineering practice, the broad goals of engineering, policy issues and institutional arrangements which affect the practice of engineering [22].

\section{IV.PROFESSIONAL AND ORGANISATIONAL CULTURES}

From the perspective of social ontology and the agency/structure relationship the traditional approach can be seen to be overly focused on the agency of engineers. As already suggested a variety of alternative approaches have been proposed. Some [23] meet the requirement, as argued for by Herkert [24], to integrate marco issues into EE by focusing on the goals of the profession. Drawing from the philosophy of technology, Son [13] has argued that a shift to a macro focus,

should lead to a questioning of the goals of engineering or current forms of technological development. He says that "...engineers will be obliged to reflect on what kind of society is desirable, to produce sound arguments for their ideas, and to conduct and justify their engineering practices accordingly". This may lead engineers to question their involvement in particular engineering projects and the pace and trajectory of technological development. While it can be agreed that there is a need to question current paths of technological development and the goals and aspirations of engineers this needs to be accompanied by proposals and strategies for change. Otherwise we will end up with a purely aspirational ethics [23] which aspires to the 'Good Society' but offers no map as to how to get there because it does not address the captive nature of the profession and the tendency of capitalism to commodify all social relations so that they become purely instrumental [25]. Raising the level of analysis to address macro issues and the broader goals of engineering is not enough unless we address the capacity of engineers to practice engineering in a way that promotes safety (and sustainability and social justice). This means changing the structural context in which they work. Son argues that this task may be beyond applied ethics as a whole "because it deals with ethical issues within existing systems, but does not necessarily try to change the system itself" [13].

A shift in emphasis would require a more sociological focus on how the practices of engineers impact on and are impacted by the social system. But this is not unproblematic. Davis [26] argues that sociological approaches to EE tend to make decisions seem inevitable as events are seen as linked by social forces rather than by individual decisions. And there is validity to this critique as some forms of sociological explanation treat humans as oversocialised "cultural dopes" who merely manifest the demands of their society. If actions are determined at this level then all ethical issues are diluted as human resistance and intervention become futile.

There is a tendency to such an approach in the much praised account of the Challenger Disaster by Vaughan [27]. Her approach is seen by some to offer the basis for a clear alternative to the focus on dilemmas facing engineers by focusing on the practice of engineers and the organisational and cultural context of that practice [17]. In explaining the disaster she emphasises institutional logics and the manner in which patterns of behaviour developed and became institutionalised within the organisations supporting the Shuttle programme. Vaughan discusses how risk came to be redefined, leading to the "normalisation of deviance" and a number of launches with a flawed design. She correctly highlights the wider economic and political environment in which NASA operated and the way it contributed to the 
normalisation of deviance. Changes in NASA's budgetary environment meant that "schedule, budget, following rules and procedures, and allegiance to hierarchy displaced safety and deference to the expertise of working engineers" [27]. Thus she not only focuses on the organisation and work groups but also the relationship between the culture of the workgroup and the wider economic and political environment. She is sceptical about the possibilities for organisational reform which does not take account of this wider environment.

While being a useful corrective to the focus on individual engineers this seems to argue for too neat a fit between the wider culture, the organisational culture and the behaviour of individuals. Drawing on particular theoretical approaches, new institutionalism and Bourdieu's concept of habitus [28], she tends to emphasis the determining role of social structures at the expense of human agency. She relies on new institutionalism to argue that the institutional context gave rise to a culture of production that led to a defective decision making process [29]. Her use of this approach leads to an emphasis on the integrating role of the organisational culture: the stress is on the unreflective and routine. The taken-for granted and unreflective nature of action is reinforced by her use of habitus to demonstrate how the institutional forces in the organisational environment become embodied in the actions of the engineers. Proponents of new institutionalism have seen it as a key concept for linking macro social forces to behaviour to explain how "actors chronically reproduce and acquiesce to social structures that are not in their interest" [30]. This would seem to leave little room for human reflection and intentionality and little possibility for change.

It is no surprise then that Freeland [31] claims that Vaughan veers too far towards an "oversocialised" conception of action "in which actors passively reproduce learned cultural scripts". A key criticism of her account is in focusing on the institutional culture she neglects the issue of power: "she replaces the study of conflict with a notion of totalising and unconscious institutional forces" [29, see also 33]. In fact the launch decision, which led to the disaster, took place under unprecedented cold conditions outside parameters that had not been previously investigated. Thus it was not normal. If universal macro forces were dominant disagreement could not have arisen. The launch was opposed by a group of engineers who knew it was outside normal parameters, rather than being embedded in an unquestioned culture [32]. In effect she is offering a particular kind of sociological explanation, with the emphasis on the organisational culture, which does not take adequate account of the capacity of people to challenge dominant cultural scripts and the social relations which provide differential access to power and resources.

It is worth noting at this point that both the traditional approach and that of Vaughan are both politically problematical in that in focusing, on the one hand, on decontextualised individuals and, on the other, the allencompassing power of institutional logics, they either do not see the need for institutional change or render engineers powerless in bringing about change. Either there is no need for change or no chance of bringing it about. In attempting to build on Vaughan's approach, and in focusing on organisational culture, Lynch and Kline do not overcome this problem. They want to assert the possibility for the imaginative prevention of the "normalisation of deviance" at the workplace. They aim "to explore how engineers can learn to identify features of their everyday practice that potentially contributes to ethically problematic outcomes before clear-cut ethical dilemmas emerge". Their approach to accident prevention remains focused on the moral responsibility of engineers and less on the changing the institutional environment in which they work [10]. This is despite Vaughan paying considerable attention to the wider economic and political environment in which NASA operated and the way it reinforced the normalisation of deviance.

Lynch and Kline's focus is on the organisational culture and they fail to adequately specify how engineers who become aware of the normalisation of deviance are to change organisational practice. They dismiss those who consider the role that engineering professional bodies, codes of ethics, trade unions, lawyers and regulatory agencies can play in bolstering responses to safety issues. In considering Lynch and Kline's approach Swierstra and Jelsma [14], argue that in "modern technology projects" the necessary conditions for individual moral agency are lacking and that the picture painted by Lynch and Kline is far too rosy. They call for a sociologically informed way of studying engineering practice, endorse the call for "an institutional ethics" and a focus on the relationship between individual moral agency on the one hand and the individual's enabling and constraining environment on the other.

\section{CRITICAL REALISM (CR)}

Vaughan offers one way of understanding this relationship with the emphasis of the determining and constraining effect of the institutional environment. Recognising the deficiencies of such an approach CR seeks to provide an account of the agency structure relationship which takes account of a properly argued view of both and the relationship between them [34]. CR argues for the primacy of ontology and that "the social ontology endorsed ... conceptualises social reality in certain terms, thus identifying what there is to be explained"[1]. Thus what society is held to be, including how we understand the relationship between structure and action, affects what constitutes "explanatory purchase on substantive social problems".

In seeking to explain social phenomena CR offers a distinctive approach [36]. Two issues are important for the purposes of this paper. Firstly, CR offers a depth ontology: a notion of a stratified reality which includes a distinction between the domain of the real (generative mechanisms), the actual (events) and the empirical (experiences). Structures of objects at the level of the real generate mechanisms that facilitate events. $\mathrm{CR}$ focuses on the identification of these mechanisms as causal factors explaining social phenomena. This is potentially emancipatory in that it forces us to consider "that certain states of affairs cannot be ameliorated within existing structures". [37]. They must be changed. 
Secondly, structures are described as generative mechanisms, because when their powers are realised they work to make things happen. Their activation is dependent on human agents. CR is committed to an explanatory model "in which the interplay between pre-existent structures, possessing causal powers...and people possessing causal powers... of their own results in contingent yet explicable outcomes" [36]. Thus any investigation can only take place at the intersection of agential and structural objects. Archer [1] argues that social theory has proposed unsatisfactory ways to understand this relationship and provides a framework for understanding different approaches by focusing on what she calls varieties of conflationism. On the one hand there is downward conflation which emphasis the determining effect of social structures and allows very little role for intentional human activity in explaining social forms. On the other hand there is upward conflation which places undue emphasis on the creative and intentional dimension of human activity and downplays the way human beings are "constrained by the way society is constructed" [34]. She identifies a third kind of central conflationism which see agency and structure as "mutually constitutive" and fundamentally inseparable. Structures are instantiated in social practices and are not seen as constituting externalised entities that constrain agency in various ways. Thus structure is collapsed into agency and their properties cannot be examined separately.

What CR seeks to do is to avoid these positions and to take account of a properly argued view of both and the relationship between them. CR is committed to analytical dualism in that structure and agency are seen as objects of a distinct type possessing different properties and powers. For the latter these include self-consciousness, reflexivity, intentionality, cognition and emotionality. The key properties of social structures are anteriority (they are pre-existing features of the world we are born into) and that they are relatively enduring. Among the powers possessed by social structures are those of enablement and constraint.

One consequence of this is that actors are capable of reflection and can formulate commitments and develop normative projects as a consequence of their deliberations upon their social situation. But we do not do this in circumstances of our own choosing: "People choose what they do, but they make their choices from a structurally and culturally determined range of options - which they do not choose" [36]. As seen above structures predates agency. While structure are dependent on activity those actions that produce a given structure may be those of a past generation. Therefore the relationship between agency and structure has to be examined over time. Once these differential temporalities of structure and agency are taken into account the close bond between the two, as argued for by central conflationists, is loosened and it becomes necessary to differentiate the two and examine their interplay. In order to do so, Archer has proposed her morphogenetic model of explanation which works on the basis of a three part cycle of analysis:

a) Structural conditioning: pre-existence structures as generative mechanisms that condition but do not determine; b) Social interaction: their interplay with other objects including agents possessing causal powers leading to

c) Structural elaboration or modification: non-predictable but explicable outcomes arising from the interactions between the above.

The model allows us to focus on the interplay between structure and agency and the possibility of change arising from social interactions. This arises because agents can reflect on their situation and formulate projects for change and structures can provide them with the power to carry them through. Thus transformation is dependent both on a commitment to change and a supportive social context.

\section{VI.CR AND ETHICS EDUCATION}

From the perspective of EE education this approach would seem to have a number of advantages. It avoids the conflationism evidenced in the approaches to EE outlined above. The traditional approach, and also that of Lynch and Kline, are forms of upward conflationism as they focus on the agency of engineers while the analysis of Vaughan suffers from downward conflationism in emphasising the determining effects of the institutional culture.

It can be noted also that while some have called for a greater integration of Science and Technology Studies (STS) into the study of EE [38] it has been argued that approaches to understanding technology and organisations associated with STS are characterised by a flat ontology associated with central conflationism and pay inadequate attention to the need to distinguish between different levels or forms of analysis. They tend to focus on the domain of the empirical and the processal character of social reality [39,40,41]. Law [42] claims that "this position is implied in the ANT (Actor Network Theory) refusal to use contextual arguments about 'social shaping' to explain the unfolding of socio-technical networks. ANT authors tend to argue that social, political, economic contexts are mobilised and enacted together with technical or scientific 'content'. The former do not shape the latter". Applying this to engineering practice he suggests we should seek to improve "the character of that practice... rather than discovering the operation of undermining external forces". But if we cannot analytically distinguish between the context and content or practice then it is impossible to understand how the social world shapes that practice and enables or constrains the actions of engineers. The ontological status and explanatory power of structure is lost [41].

$\mathrm{CR}$ encourages us to examine ethical issues in a manner which focus underlying generative mechanisms, the interactions between them and their impacts on engineering practice over time. It "forces us to look at deeper structural things that might be the cause of events" [35] like the underlying organisational, economic and political factors identified in the discussion of accidents above. But it also encourages us to consider the capacity of engineers (as social agents) to influence organisational practices. In this context a key issue is the extent to which dominant views are contestable [32] and the manner in which engineers are 
enabled to contest dominant views and promote change. Thus the promotion of an institutional ethics is useful, but does not resolve all issues in that regulation has to be fought for and implemented [20]. Therefore CR provides a theoretical basis for placing second order responsibilities on engineers to strive for the creation of supportive social environments which enable their social responsibility [10]. Arising from this we are required to examine the interventions of engineers in the public policy domain and how they contribute to the structural conditioning of engineering practice and whether the resulting laws, regulation and practices contribute to structural elaboration or modification. By focusing on the interaction of agential and structural objects CR avoids the moralism of the traditional approach and the determinism of those who argue for the overarching influence of organisational culture in explaining accidents and disasters.By attempting to identify the structural and material preconditions for successful interventions in the world a CR approach can put us in a better position to identify impediments to change at the level of the real and address underlying causes of phenomena such as accidents. One outcome of this may be a more effective approach to accident prevention.

\section{VII. - CONCLUSIONS}

This paper has argued that there are deficiencies in the dominant approach to engineering ethics and some proposed alternatives. A more adequate approach can draw on CR to shift the emphasis from the teaching of moral reasoning and a narrow focus on values and attitudes to a concern with the integration into engineering programmes of the social and institutional context of engineers work and the role of engineers in promoting policy changes and social practices that change these social contexts and enable social responsibility [see 43]. This should force us to ask our students to consider what alternative models of engineering practice are available other than those located within profit driven and hierarchically organised corporations [7, 22]. This would require a focus on the use of history, politics, organisation and social theory in engineering programmes and may move us far from teaching ethics as traditionally understood and to a greater focus on social policy. This may raise the question as to whether all those apparently engaged in teaching engineering ethics are actually involved in the same enterprise as the emphasis shifts from moral decision making to concerns about the social context in which engineering takes place [44]. But surely this is a less interesting question than one that focuses on what is actually required in engineering education to enable future engineers to understand the full range of issues they will be required to address in order hold paramount the health, safety and welfare of the public.

\section{REFERENCES}

[1] M. Archer, Realist Social Theory. Cambridge University Press, 1995.

[2] T.Mac Sheoin, "Chemical catastrophe: From Bhopal to BP Texas City", Monthly Review, 62 (2), September 2010.
[3] J.C. Le Coze, "BP Texas City accident:weak signals or sheer power", $3^{\text {rd }}$ Symposium on Resilience Engineering, Juan-Les-Pin, France, October, 2008

[4] N.Pidgeon, "The psychology of risk" in D. Blockley (ed) Engineering Safety, Maidenhead: Mc Graw Hill, 1992.

[5] N.Pidgeon, “Complex organizational failures: culture, high reliability, and the lessons from Fukushima". The Bridge, Fall 2012.

[6] Y. Dien, Y., M. Llory, and R. Montmayeul, "Organisational accidents investigation methodology and lessons learned". Journal of Hazardous Materials, 111(1-3), 2004, 147-153.

[7] S.Tombs, "Corporate Violence", in Brookman, F., Pierpoint, H., Bennett, T. and Maguire, M., eds. Handbook on Crime, Cullompton: Willan, 2010, 884-903.

[8] S. Tombs, "A political economy of corporate killing”, Criminal Justice Matters, 70 (1), $29-30$

[9] D. Riley, "Resisting neoliberalism in global development engineering", $114^{\text {th }}$ ASEE Annual Conference, Hawaii 2007.

[10] E. Conlon, and H. Zandvoort, "Broadening Ethics Teaching In Engineering: Beyond The Individualistic Approach". Science and Engineering Ethics. 17 (2), 2010, 217-232.

[11] J.L. Hess. "Global portrayals of engineering ethics education: A systematic literature review", American Society for Engineering Education Annual Conference, Atlanta, June 2013

[12] A. Colby, and W.M. Sullivan, W.M. "Teaching ethics in undergraduate engineering education". Journal of Engineering Education, 97 (3), 2008, 327-338.

[13] W.C. Son, "Philosophy of technology and micro-ethics in engineering." Science and Engineering Ethics, 14(3), 2008, 405-415.

[14] T. Swiestra and J.Jelsma, "Responsibility without moralism in technoscientific design practice." Science, Technology and Human Values, 31(3), 2006, 309-332.

[15] C.E. Harris Harris, M.S. Pritchard and M. Rabins, Engineering Ethics. 4th ed., Belmount: Wadsworth, 2009.

[16] M. Davis, Thinking Like An Engineer. Oxford Univerity Press, 1998.

[17] W.T Lynch. and R. Kline, Engineering Practice And Engineering Ethics. Science, Technology and Human Values, 25 (2), 2000, 195-225.

[18] E.Conlon, "Broadening engineering education: Bringing the community in". Science and Engineering Ethics, 19 (4), 2013, 1589-1594.

[19] S. Pfatteicher, "Teaching vs. preaching: EC2000 and the engineering ethics dilemma." Journal of Engineering Education, 90(1), 2001, 137142 .

[20] M. Coeckelbergh, "Regulation or responsibility? Autonomy, moral imagination and engineering". Science,Technology and Human Values, 31(3), 2006, 237-260.

[21] H. Zandvoort, “Good engineers need good laws”. European Journal of Engineering Education, 30(1), 2005, 21-36.

[22] E. Conlon, "Macro, Micro, Structure, Agency: Analysing Approaches To Engineering Ethics”. SEFI Annual Conference, Lisbon, September, 2011.

[23] W.R. Bowen, Engineering Ethics: Outline Of An Aspirational Approach. London: Springer. 2009.

[24] J.R. Herkert, "Ways Of Thinking About And Teaching Ethical Problem Solving: Microethics And Macroethics In Engineering”. Science and Engineering Ethics, 11(3), 2005, 373-385.

[25] G. Moriarity, The Engineering Project, Penn State Press, 2008. 
[26] M. Davis, "Engineering ethics, individuals and organisations", Science and Engineering Ethics, 12 (2), 2006, 223-231.

[27] D. Vaughan, The Challenger Launch Decision. University of Chicago Press. 1996.

[28] D. Vaughan, "Bourdieu and organisations: the empirical challenge." Theory and Society,37, 2008, 65-81.

[29] S.P. Feldman, "Micro matters: The aesthetics of power in NASA's flight readiness review", The Journal of Applied Behavioral Science, 36 (4), 2000, 474-490.

[30] W.W. Powell and P.J. Di Maggio (1991). The New Institutionalism In Organisational Analysis. University of Chicago Press, 1991.

[31] R.E. Freeland, "Culture and volition in organisational decision-making", Qualitative Sociology, 20,(1), 1997,127-37.

[32] P.K. Edwards and J. Wajcman, The Politics Of Working Life. Oxford University Press. 2005.

[33] C. Perrow. Normal Accidents. New Jersey: Princeton University Press, 1996.

[34] D. Scott, Realism and Educational Research: New Perspectives and Possibilities. London: Routledge, 2000.

[35] L.Kotta, Engineering education, practice, and engineering research: critical realist insights. Proceedings of the AAEE Conference, Freemantle, 2011, 19-29.
[36] B. Carter, B. and C. New, C. "Introduction: realist social theory and empirical research". In B. Carter and C. New (eds), Making Realism Work, Abingdon: Routledge, 2004

[37] A.Collier, Critical Realism. London: Verso, 1994.

[38] D.G Johnson, and J.M Wet more, "STS And Ethics: Implications For Engineering Ethics" Handbook of Science and Technology Studies. MIT Press. 2007.

[39] D. Elder-Vass, "Searching for realism, structure and agency in Actor Network Theory". British Journal of Sociology, 59 (3), 2008, 455-73.,

[40] H.K. Klein and D.L Kleinman 2002, "The social construction of technology: Structural considerations." Science, Technology and Human Values, 27 (1), 2002, 28-52.

[41] M. Reed, "In praise of duality and dualism:Rethinking agancy and structure in organisational analysis. Organisation Studies, 18 (1), 1997, 21-42.

[42] John Law, "Disasters, A/symmetries and Interferences", Centre for Science Studies, Lancaster University [Online] http://www.comp.lancs.ac.uk/sociology/papers/Law-DisastersAsymmetries-andInterferences.pdf (25 April 2015).

[43] M.H. Wisnioski, Engineers for Change. MIT Press, 2012.

[44] M. Davis, "Engineers and sustianbility", Journal of Applied Ethics and Philosophy 2, 2010, 12-20. 